\title{
Fruit and Vegetable Consumption Among Adults in the United States, 2015-2018
}

\author{
Nicholas Ansai, M.P.H., and Edwina A. Wambogo, Ph.D., M.S., M.P.H., R.D.
}

\section{Key findings}

\section{Data from the National Health and Nutrition Examination Survey, 2015-2018}

- More than two-thirds $(67.3 \%)$ of adults aged 20 and over consumed any fruit on a given day, and fruit consumption was higher among women $(70.5 \%)$ compared with men $(63.8 \%)$.

- Approximately 95\% of adults consumed any vegetables on a given day.

- The percentage of adults who consumed any fruit; citrus, melon, or berries; and other types of whole fruit on a given day increased with income.

- The percentage of adults who consumed dark green, red and orange, other vegetables, and any vegetable types on a given day increased with income.

- The percentage of adults who consumed any fruit on a given day decreased from $77.2 \%$ in $1999-2000$ to $64.9 \%$ in 2017-2018, but there was no change in the percentage consuming any vegetables.
The Dietary Guidelines for Americans, 2015-2020 suggest that a healthy eating pattern include consuming a variety of different fruit and vegetables (1). Fruits and vegetables are sources of many essential nutrients, such as vitamins, minerals, and fiber, and consumption is associated with decreased risk of chronic disease (1-3). This report examines the percentage of adults aged 20 and over who consumed fruit and vegetables on a given day by sex and income in 2015-2018 and trends in fruit and vegetable consumption.

\section{What percentage of adults consumed fruit on a given day in 2015-2018, and were there differences by sex?}

In 2015-2018, more than two-thirds (67.3\%) of adults aged 20 and over consumed any fruit on a given day; $29.7 \%$ consumed citrus, melons, or berries; $47.5 \%$ consumed other whole fruit; and $30.8 \%$ consumed $100 \%$ fruit juice (Figure 1).

Figure 1. Percentage of adults aged 20 and over who consumed fruit on a given day, by sex: United States, 2015-2018

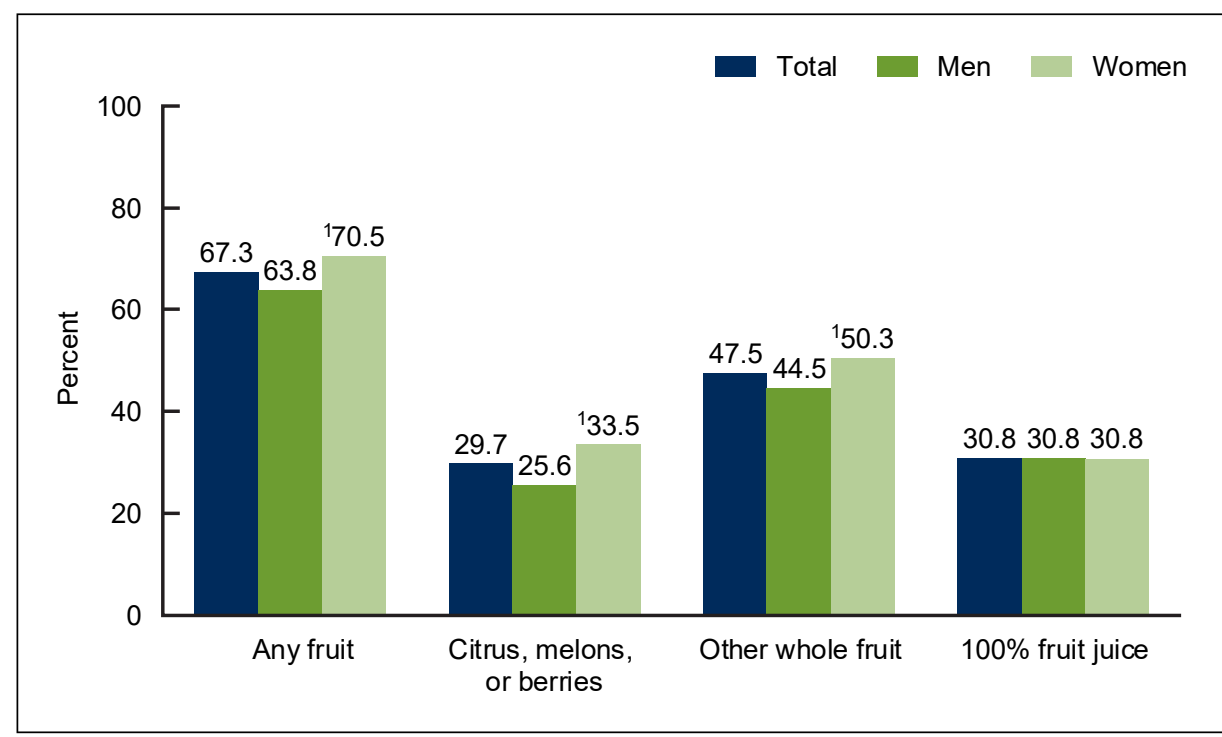

${ }^{1}$ Significantly different than men.

NOTES: Percentages are based on Food Patterns Equivalents Database food groups. Access data table for Figure 1 at: https://www.cdc.gov/nchs/data/databriefs/db397-tables-508.pdf\#1.

SOURCE: National Center for Health Statistics, National Health and Nutrition Examination Survey, 2015-2018.

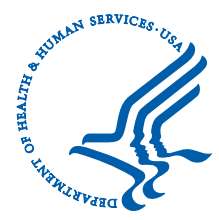




\section{NCHS Data Brief a No. 397 a February 2021}

A higher percentage of women (70.5\%) compared with men (63.8\%) consumed any fruit on a given day. Similarly, a higher percentage of women than men consumed citrus, melons, or berries (33.5\% and $25.6 \%$, respectively) and other whole fruit (50.3\% and $44.5 \%)$. No difference was seen in the percentage of men (30.8\%) and women (30.8\%) who consumed $100 \%$ fruit juice.

\section{What percentage of adults consumed vegetables on a given day in 2015-2018, and were there differences by sex?}

Among adults aged 20 and over, $95.1 \%$ consumed any vegetables on a given day; $26.3 \%$ consumed dark green vegetables; $79.2 \%$ consumed red and orange vegetables; $50.3 \%$ consumed starchy vegetables; and $78.8 \%$ consumed other vegetables (Figure 2).

A higher percentage of women consumed dark green (30.0\%) and starchy vegetables $(51.7 \%)$ on a given day, compared with men $(22.3 \%$ and $48.8 \%$, respectively). No significant differences were seen in the percentage of men and women who consumed any vegetables $(95.0 \%$ for men and $95.3 \%$ for women), red and orange vegetables (79.7\% for men and $78.7 \%$ for women), and other vegetables $(77.6 \%$ for men and $79.9 \%$ for women).

Figure 2. Percentage of adults aged 20 and over who consumed vegetables on a given day, by sex: United States, 2015-2018

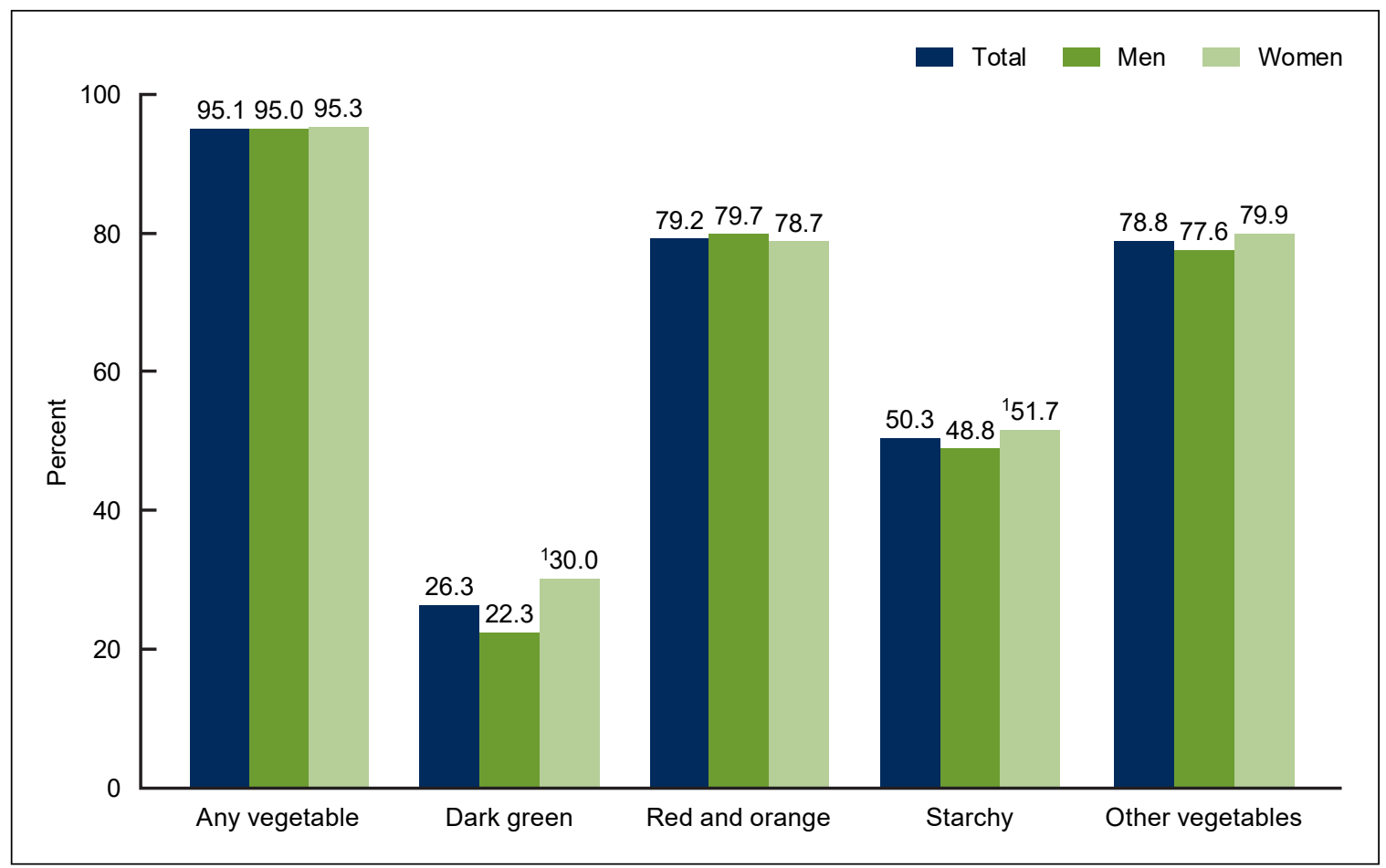

${ }^{1}$ Significantly different than men.

NOTES: Percentages are based on Food Patterns Equivalents Database food groups. Access data table for Figure 2 at:

https://www.cdc.gov/nchs/data/databriefs/db397-tables-508.pdf\#2.

SOURCE: National Center for Health Statistics, National Health and Nutrition Examination Survey, 2015-2018. 


\section{NCHS Data Brief a No. 397 a February 2021}

\section{Were there differences by income in the percentage of adults who consumed fruit on a given day in 2015-2018?}

The percentage of adults aged 20 and over who consumed any fruit increased with increasing family income, from $60.3 \%$ of adults from families with incomes less than $130 \%$ of the federal poverty level (FPL) to $64.5 \%$ of adults from families with incomes between $130 \%$ and $349 \%$ of FPL to $72.9 \%$ of adults from families with incomes at or greater than $350 \%$ of FPL (Figure 3 ).

Similarly, the percentage of adults who consumed citrus, melons, or berries $(21.3 \%, 26.2 \%$, and $36.6 \%$ for each income group) and other whole fruit $(39.2 \%, 45.1 \%$, and $53.3 \%$ for each income group), increased with increasing family income. No significant differences existed by income in the percentage of adults who consumed $100 \%$ fruit juice on a given day $(31.5 \%, 29.7 \%$, and $31.8 \%$ for each income group).

Figure 3. Percentage of adults aged 20 and over who consumed fruit on a given day, by income: United States, 2015-2018

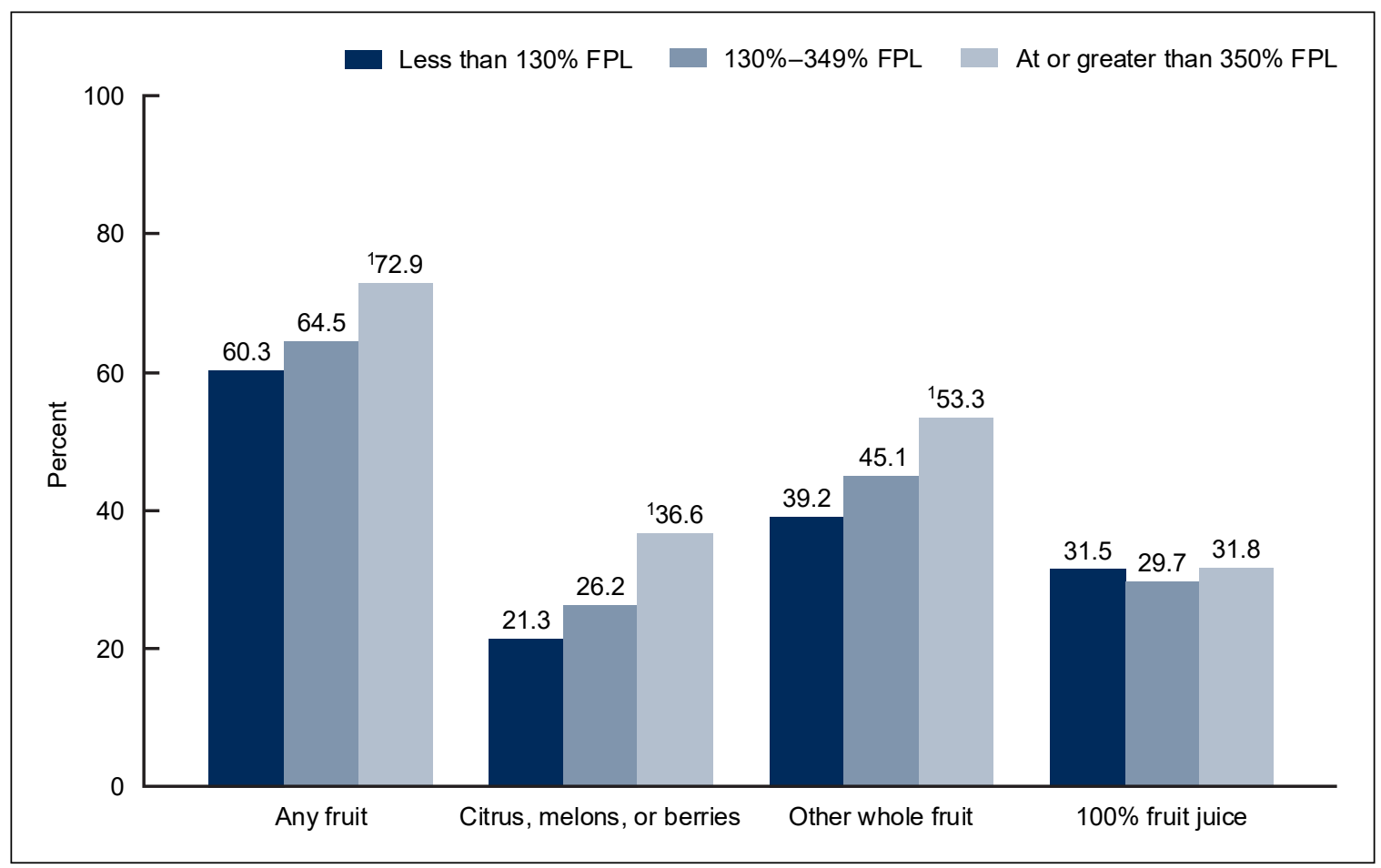

${ }^{1}$ Significant linear increasing trend with increasing income.

NOTES: FPL is federal poverty level. Percentages are based on Food Patterns Equivalents Database food groups. Access data table for Figure 3 at: https://www.cdc.gov/nchs/data/databriefs/db397-tables-508.pdf\#3.

SOURCE: National Center for Health Statistics, National Health and Nutrition Examination Survey, 2015-2018. 


\section{NCHS Data Brief a No. 397 a February 2021}

\section{Were there differences by income in the percentage of adults who consumed vegetables on a given day in 2015-2018?}

The percentage of adults aged 20 and over who consumed any vegetables increased with increasing family income, from $92.5 \%$ of those from families with incomes less than $130 \%$ of FPL to $94.4 \%$ of those from families with incomes between $130 \%$ and $349 \%$ of FPL to $97.1 \%$ of those from families with incomes at or greater than $350 \%$ of FPL (Figure 4 ).

Likewise, the percentage of adults who consumed dark green vegetables $(20.4 \%, 23.2 \%$, and $32.0 \%$ for each income group), red and orange vegetables $(74.7 \%, 78.1 \%$, and $82.8 \%$ for each income group), and other vegetables (73.0\%, 76.9\%, and $83.6 \%$ for each income group), increased with increasing family income. There were no significant differences by income in the percentage of adults who consumed starchy vegetables $(51.5 \%, 52.0 \%$, and $48.9 \%$ for each income group).

Figure 4. Percentage of adults aged 20 and over who consumed vegetables on a given day, by income: United States, 2015-2018

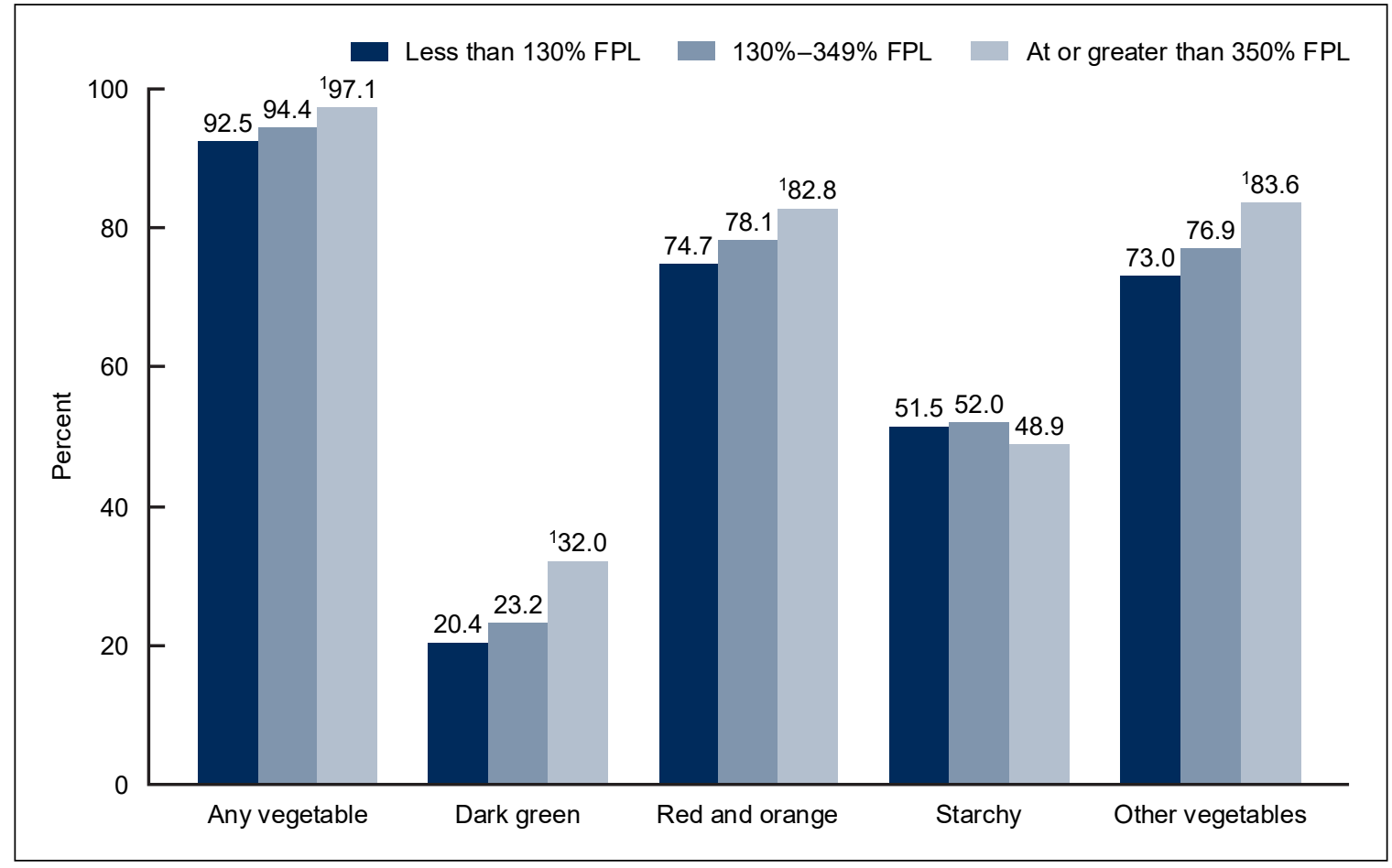

${ }^{1}$ Significant linear increasing trend with increasing income.

NOTES: FPL is federal poverty level. Percentages are based on Food Patterns Equivalents Database food groups. Access data table for Figure 4 at: https://www.cdc.gov/nchs/data/databriefs/db397-tables-508.pdf\#4.

SOURCE: National Center for Health Statistics, National Health and Nutrition Examination Survey, 2015-2018. 


\section{NCHS Data Brief a No. 397 a February 2021}

\section{Were there trends in the percentage of adults consuming any fruit or vegetables on a given day from 1999-2000 through 2017-2018?}

The percentage of adults who consumed any fruit on a given day decreased from $77.2 \%$ in 1999-2000 to 64.9\% in 2017-2018 (Figure 5).

There was no change in the percentage of adults who consumed any vegetables on a given day between 1999-2000 (95.3\%) and 2017-2018 (95.0\%).

Figure 5. Percentage of adults aged 20 and over who consumed any fruit or vegetables on a given day: United States, 1999-2000 through 2017-2018

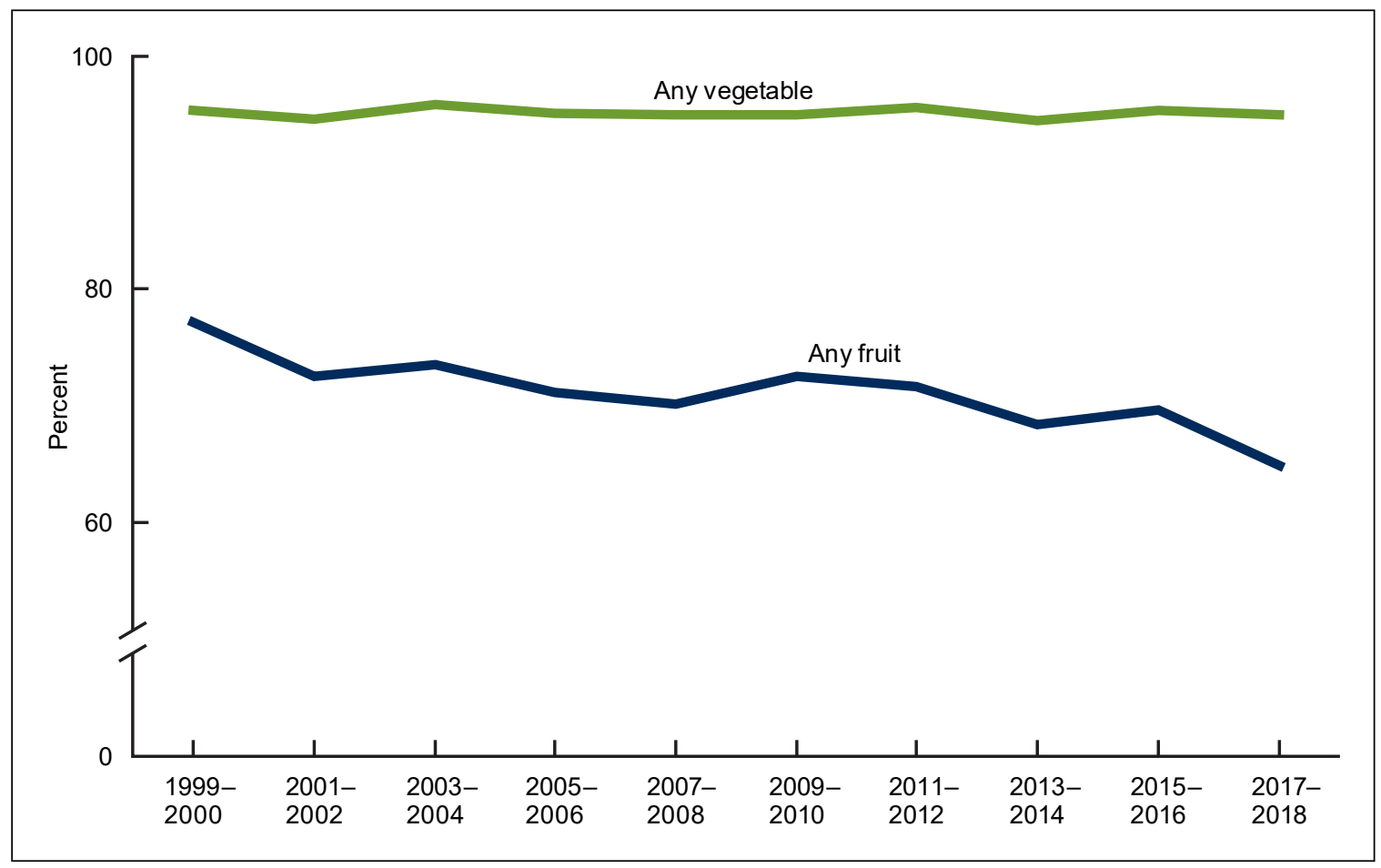

${ }^{1}$ Significant decreasing linear trend.

NOTES: Percentages are based on Food Patterns Equivalents Database food groups. Access data table for Figure 5 at:

https://www.cdc.gov/nchs/data/databriefs/db397-tables-508.pdf\#5.

SOURCE: National Center for Health Statistics, National Health and Nutrition Examination Survey, 1999-2000 through 2017-2018. 


\section{Summary}

In 2015-2018, more than two-thirds of adults aged 20 and over consumed any fruit $(67.3 \%)$, and approximately $95 \%$ consumed any vegetables on a given day. A higher percentage of women consumed fruit compared with men across all fruit categories except for $100 \%$ fruit juice where there was no difference by sex. Similarly, a higher percentage of women consumed dark green and starchy vegetables on a given day compared with men. Consumption of both fruits and vegetables increased with income, except for $100 \%$ fruit juice and starchy vegetables. A decrease was observed in the percentage of adults consuming any fruit on a given day between 1999-2000 through 2017-2018, but there was no change in the percentage of adults consuming any vegetables over the same time period.

Healthy People 2030 objectives include increasing the overall consumption of fruits and vegetables among people aged 2 years and over to help individuals obtain the recommended amounts of healthy and nutritious foods to reduce their risk for chronic diseases and improve their health (4).

\section{Definitions}

Food categories: Food categories were defined using the USDA's Food Patterns Equivalents Database (FPED), formerly known as the MyPyramid Equivalents Database (MPED) (5). FPED separates all foods reported in the National Health and Nutrition Examination Survey (NHANES) into individual ingredients and assigns those ingredients to food groups and subgroups. The fruit food groups include citrus, melons, or berries; other fruit; and 100\% fruit juice. The vegetable food groups include dark green vegetables (such as spinach, collard greens, and broccoli); red and orange vegetables (such as carrots, red peppers, and tomatoes); starchy vegetables (such as potatoes, plantains, and cassava); and other vegetables (such as cauliflower, string beans, and eggplant). The MPED 1.0, MPED 2.0, and FPED files from 2005-2006 through 2017-2018 were used in this analysis.

Federal poverty level: Levels are based on the income to poverty ratio, which is the ratio of annual total family income to the U.S. Department of Health and Human Services poverty guidelines, after accounting for inflation and family size (6).

\section{Data source and methods}

NHANES is a series of cross-sectional, nationally representative surveys of the civilian noninstitutionalized U.S. population administered by the National Center for Health Statistics to assess the diet, health, nutritional status, and health-related behaviors of the U.S. population. It combines an in-home interview and a standardized physical examination at a mobile examination center (MEC). Details of the NHANES study design, implementation, data sets, analytic considerations, and other documentation are available online (7).

This report uses dietary data collected via an in-person 24-hour dietary recall using the U.S. Department of Agriculture's standardized Automated Multiple Pass Method. Dietary recalls cover foods and beverages consumed on the day (midnight to midnight) before the examination in the MEC. Limitations associated with self-reported dietary data, such as misreporting, have been 


\section{NCHS Data Brief a No. 397 a February 2021}

described (8). Despite these limitations, dietary recalls have use in assessing population level estimates $(7,9)$.

Data were analyzed using the day 1 dietary recall sample weights to account for differential probabilities of selection, nonresponse, noncoverage, and day of the week. The standard errors of the percentages were estimated using Taylor series linearization, a method that incorporates the sample design.

Differences between groups were evaluated using $t$ statistics. Tests for linear trends by age and income were evaluated using orthogonal polynomials. Statistical testing was based on a $p$ value less than 0.05 significance level. All differences reported are statistically significant unless otherwise indicated. Statistical analyses were conducted using SAS version 9.4 (SAS Institute, Cary, N.C.) and SUDAAN version 11.0 (RTI International, Research Triangle Park, N.C.).

\section{About the authors}

Nicholas Ansai and Edwina A. Wambogo are with the National Center for Health Statistics, Division of Health and Nutrition Examination Surveys.

\section{References}

1. U.S. Department of Health and Human Services, U.S. Department of Agriculture. 2015-2020 Dietary Guidelines for Americans, 8th ed. 2015. Available from: https://health.gov/our-work/ food-nutrition/2015-2020-dietary-guidelines/guidelines/.

2. U.S. Department of Agriculture. Nutrients and health benefits. Available from: https://www. myplate.gov/eat-healthy/vegetables\#mp-container-706386.

3. Slavin JL, Lloyd B. Health benefits of fruits and vegetables. Adv Nutr 3(4):506-16. 2012.

4. U.S. Department of Health and Human Services, Office of Disease Prevention and Health Promotion. Healthy People 2020 topics and objectives: Nutrition and weight status. 2020.

Available from: https://health.gov/healthypeople/objectives-and-data/browse-objectives/nutritionand-healthy-eating.

5. Bowman SA, Clemens JC, Shimizu M, Friday JE, Moshfegh AJ. Food patterns equivalents database 2015-2016: Methodology and user guide. Beltsville, MD: Food Surveys Research Group, Beltsville Human Nutrition Research Center. 2018.

6. Chen TC, Clark J, Riddles MK, Mohadjer LK, Fakhouri THI. National Health and Nutrition Examination Survey, 2015-2018: Sample design and estimation procedures. National Center for Health Statistics. Vital Health Stat 2(184). 2020.

7. Ahluwalia N, Dwyer J, Terry A, Moshfegh A, Johnson C. Update on NHANES dietary data: Focus on collection, release, analytical considerations, and uses to inform public policy. Adv Nutr 7(1):121-34. 2016.

8. Subar AF, Freedman LS, Tooze JA, Kirkpatrick SI, Boushey C, Neuhouser ML, et al. Addressing current criticism regarding the value of self-report dietary data. J Nutr 145(12):263945. 2015. 


\section{U.S. DEPARTMENT OF \\ HEALTH \& HUMAN SERVICES}

FIRST CLASS MAIL

POSTAGE \& FEES PAID

$\mathrm{CDC} / \mathrm{NCHS}$

Centers for Disease Control and Prevention

PERMIT NO. G-284

National Center for Health Statistics

3311 Toledo Road, Room 4551, MS P08

Hyattsville, MD 20782-2064

OFFICIAL BUSINESS

PENALTY FOR PRIVATE USE, $\$ 300$

For more NCHS Data Briefs, visit:

https://www.cdc.gov/nchs/products/databriefs.htm.

\section{NCHS Data Brief a No. 397 a February 2021}

9. Hébert JR, Hurley TG, Steck SE, Miller DR, Tabung FK, Peterson KE, et al. Considering the value of dietary assessment data in informing nutritionrelated health policy. Adv Nutr 5(4):447-55. 2014.

Keywords: diet $\bullet$ National Health and Nutrition Examination Survey (NHANES)

\section{Suggested citation}

Ansai N, Wambogo EA. Fruit and vegetable consumption among adults in the United States, 2015-2018. NCHS Data Brief, no 397. Hyattsville, MD: National Center for Health Statistics. 2021. DOI: https://dx.doi.org/10.15620/cdc:100470.

\section{Copyright information}

All material appearing in this report is in the public domain and may be reproduced or copied without permission; citation as to source, however, is appreciated.

\section{National Center for Health Statistics}

Brian C. Moyer, Ph.D., Director Amy M. Branum, Ph.D., Acting Associate Director for Science

Division of Health and Nutrition

Examination Surveys

Ryne Paulose-Ram, M.A., Ph.D., Acting

Director

Lara J. Akinbami, M.D., Acting Associate Director for Science

For e-mail updates on NCHS publication releases, subscribe online at:

https://www.cdc.gov/nchs/email-updates.htm.

For questions or general information about NCHS:

Tel: 1-800-CDC-INFO (1-800-232-4636)

TTY: $1-888-232-6348$

Internet: https://www.cdc.gov/nchs

Online request form: https://www.cdc.gov/info

ISSN 1941-4927 Print ed.

ISSN 1941-4935 Online ed. 